\title{
Indirect Assessment of Oxygen Requirements in Newborn Babies by Monitoring Deep Body Temperature
}

\author{
J. W. SCOPES and IQBAL AHMED \\ From the Nuffield Neonatal Research Unit, Institute of Child Health, Hammersmith Hospital, London
}

The general availability of pure $\mathrm{O}_{2}$ in cylinders gave medicine a powerful therapeutic tool. Until 1952 oxygen was used freely in high concentrations in many premature baby units, in the knowledge that many babies were hypoxic and on the assumption that it would in any case do no harm. The demonstration that high concentrations of inspired $\mathrm{O}_{2}$ could lead to retrolental fibroplasia in premature babies (Patz, Hoeck, and De La Cruz, 1952) led to more caution, and it became a generally accepted practice to restrict added $\mathrm{O}_{2}$ so that inspired concentrations never exceeded $40 \%$ (Kinsey, 1956). This seemed particularly reasonable in view of the demonstration (Campbell, 1960) that $\mathrm{O}_{2}$ concentrations of $40 \%$ would be able to overcome any diffusion defect which at that time was thought to be the main cause of hypoxia in hyaline membrane disease (Craig, Fenton, and Gitlin, 1958). However, it has subsequently been shown that adherence to this limit may lead to an increased mortality in premature babies with respiratory distress (Avery and Oppenheimer, 1960) and to a higher incidence of neurological abnormality of the type associated with hypoxia (McDonald, 1963). Warley and Gairdner (1962) and Gupta (personal communication) have shown that individual babies with the respiratory distress syndrome may be grossly hypoxic in concentrations of inspired $\mathrm{O}_{2}$ as high as $40 \%$, and that increasing the $\mathrm{O}_{2}$ concentration to levels previously considered dangerous may be necessary to achieve anything like a satisfactory $\mathrm{Po}_{2}$ in the baby's arterial blood. There is now evidence from kittens that it is high $\mathrm{O}_{2}$ tensions in the blood, rather than high concentrations of ambient $\mathrm{O}_{2}$, that lead to retrolental fibroplasia (Ashton, 1964). The clinician is therefore in a dilemma: individual babies are liable to retrolental fibroplasia if exposed to high $\mathrm{O}_{2}$ concentrations, while other babies will

Received April 26, 1965. suffer death or neurological damage if high $\mathrm{O}_{2}$ concentrations are withheld. What is more, both situations may occur at different times in the same baby.

Assessing a baby's $\mathrm{O}_{2}$ requirements is made very difficult by lack of data on which to base a judgement. The most reliable way of determining $\mathrm{O}_{2}$ requirements is by direct measurement of $\mathrm{Po}_{2}$ in arterial blood. This carries with it the disadvantage of having to obtain arterial blood from a sick infant and of needing special facilities and equipment. The clinician has to depend on signs such as the presence or absence of cyanosis, respiratory irregularity, restlessness (rarely present in hypoxic premature babies), and frequency of apnoeic spells. Any or all of these signs may be useful but none can be said to be entirely reliable. For instance, babies who are grossly hypoxic are not always obviously cyanosed. Additional information would undoubtedly be valuable, and we believe that in certain circumstances this is provided by monitoring the rectal temperature, which can then be used as a guide to $\mathrm{O}_{2}$ requirements (Davis and Tizard, 1961).

\section{Theoretical Background}

It has been shown in babies (Oliver and Karlberg, 1963) as in many newborn mammals, e.g. cat (Hill, 1959), rabbit (Adamsons, 1959), monkey (Dawes, Jacobson, Mott, and Shelley, 1960), guinea-pig (Dawes and Mestyán, 1963), that moderate hypoxia impairs the ability to increase heat production in response to a cool environment, resulting in a fall in deep body temperature. Fig. 1 shows a model of the situation in homeothermic newborn animals. In the temperature range known as the neutral range, $\mathrm{O}_{2}$ consumption and, therefore, heat production is minimal. The environmental temperature below which the oxygen consumption starts to 

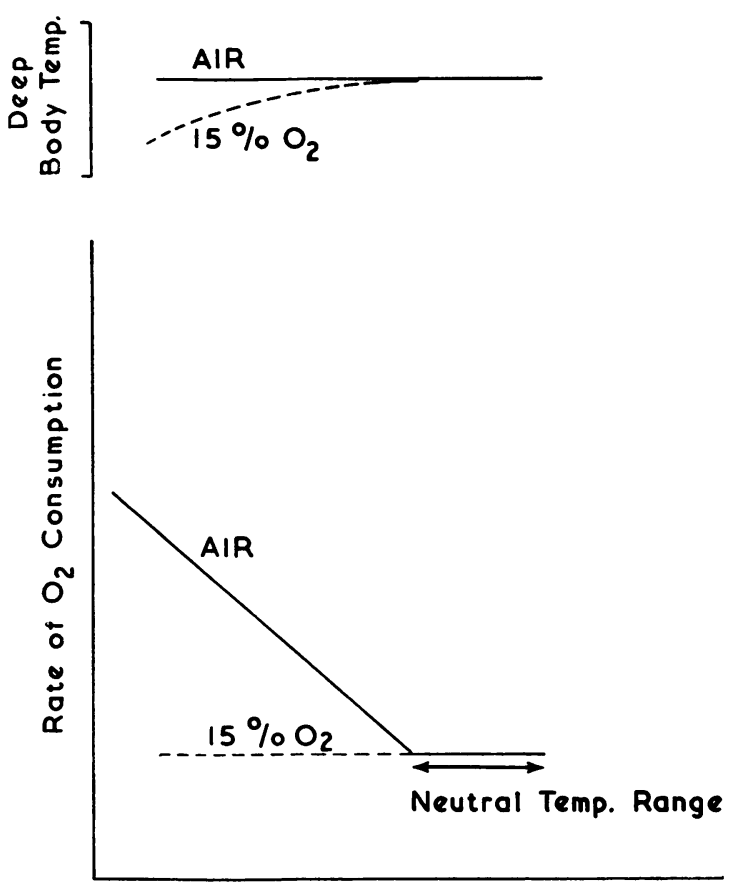

FIG. 1.-A diagram of the relation between metabolic rate, rectal temperature, and environmental temperature in the newborn mammal.

rise is known as the critical temperature. Below this environmental temperature, $\mathrm{O}_{2}$ consumption must be increased if the deep body temperature is to be maintained. It follows that if the ability to increase $\mathrm{O}_{2}$ consumption is impaired by hypoxia the deep body temperature will fall. If the hypoxia is corrected, the $\mathrm{O}_{2}$ consumption, and later the deep body temperature, will rise. Conversely, the ability to maintain the deep body temperature at environmental temperatures below the neutral range implies that the baby is not seriously hypoxic. This argument is known to apply to a normal newborn baby breathing air and low oxygen mixtures, respectively (Oliver and Karlberg, 1963). It is reasonable to suppose that in babies with inadequate respiratory exchange (respiratory distress, pneumonia, etc.) the argument will also apply as between oxygen-enriched mixtures and air, and that information so obtained might be of use clinically. Given a constant thermal environment the necessary information can be obtained by measuring the deep body temperature or, more certainly, by measuring the $\mathrm{O}_{2}$ consumption directly (see Tizard, 1964).

\section{Methods}

The observations reported here were made on babies in the Neonatal Ward of the Hammersmith Hospital. This ward admits newborn babies needing special care, the majority of whom are premature, but a substantial minority are term babies with a wide variety of clinical conditions. Over the past 18 months, more than 300 oxygen consumption studies have been made on over 100 of these babies in an investigation into temperature control in newborn babies, under various conditions of sickness and health. The babies reported in this paper were studied in the course of this investigation, and all showed clinical or laboratory evidence of hypoxia. In many of them, hypoxaemia was confirmed by measurement of arterial $\mathrm{Po}_{2}$. The commonest clinical condition was that of 'hyaline membrane disease' (the respiratory distress syndrome of the newborn). This group of hypoxic babies includes those with birth weights varying between 780 and $3,000 \mathrm{~g}$. and gestations between 28 weeks and 41 weeks.

In a minority of studies a standard ward incubator (Oxygenaire) was used. To prevent undue fluctuations in the environmental temperature, the heat control was checked over the period of observation and adjusted manually where necessary. Rectal temperature was measured by an electrical thermometer (thermistor or thermocouple) inserted at least $10 \mathrm{~cm}$. into the child's colon (Karlberg, 1949) and strapped in place with adhesive tape. $\mathrm{O}_{2}$ concentrations in the incubator were frequently checked, using a paramagnetic $\mathrm{O}_{2}$ analyser (Beckman). Throughout the period of observation, nursing procedures were reduced to a minimum to prevent fluctuations in environmental temperature and $\mathrm{O}_{2}$ concentration.

In the majority of the studies, the baby was placed in a specially constructed incubator in which minute by minute $\mathrm{O}_{2}$ consumption is measured and recorded. With this incubator, one can select any environmental temperature and any $\mathrm{O}_{2}$ concentration which then stay constant to within $0.1^{\circ} \mathrm{C}$. or $0.1 \% \mathrm{O}_{2}$, over the period of abservation. Heat exchange by radiation is controlled by opaque walls at the temperature of the ambient air. Rectal temperature was monitored as before and the child's clinical condition (colour, respiration, activity) was constantly watched. Where arterial $\mathrm{PO}_{2}$ was measured, blood was taken from an indwelling umbilical artery catheter into a heparinized syringe, the $\mathrm{Po}_{2}$ being measured immediately on a Clark's electrode (Beckman macro electrode, sample size $0.2 \mathrm{ml}$. blood).

\section{Results}

On numerous occasions in the course of the wider investigation, reducing the environmental temperature to below the critical temperature produced a negligible or only a small increase in $\mathrm{O}_{2}$ consumption, with the result that rectal temperature began to fall. On at least 21 occasions, increasing the concentration of $\mathrm{O}_{2}$ in the atmosphere by $20 \%$ or more, without changing other environmental 
conditions, caused a substantial increase in the rate of oxygen consumption. The normal baby's metabolic response in these circumstances is not affected by increasing the atmospheric $\mathrm{O}_{2}$ concentration (Oliver and Karlberg, 1963; Scopes, unpublished data), so that this substantial rise suggested that the babies concerned were hypoxic before the added $\mathrm{O}_{2}$ was given. In 11 of the babies concerned, the fall in body temperature was prevented or the rate of fall was reduced during the period concerned, usually 10 to 20 minutes. In the other 10 no change in the rate of fall could be seen in this short period, despite the increase in oxygen consumption. The lower environmental temperature chosen was usually between 26 and $29^{\circ} \mathrm{C}$., and the increase in oxygen consumption effected by adding $\mathrm{O}_{2}$ was from 10 to $50 \%$. In babies in whom there was undoubted severe anoxia (see individual cases), the increase was between 36 and $50 \%$. These observations are seen in better perspective when individual cases are described in detail. In some of these cases oxygen consumption together with rectal temperature was being measured, in others the rectal temperature alone was recorded while the baby was in the nursing incubator.

Case 1 (Fig. 2). This coloured baby was born at 41 weeks' gestation weighing $2,980 \mathrm{~g}$. The mother was given pethidine, $100 \mathrm{mg}$. intramuscularly, one hour before delivery. During labour the foetal heart rate fell to 100 and delivery was assisted by use of the vacuum extractor. At birth the child breathed at once. At 1 minute the child was in good condition with a heart rate of 148 per minute, crying, pink, and with good limb tone. Having been born at 11 p.m. she spent the night in the nursery and appeared quite well, but at 8 a.m. next morning she was found to have a rectal temperature of $31 \cdot 1^{\circ} \mathrm{C}$. There was no distress or cyanosis and apart from her low temperature no abnormality was found on clinical examination.

When the baby was placed in the oxygen consumption incubator she had already been warmed to $33^{\circ} \mathrm{C}$. At an environmental temperature of $33^{\circ} \mathrm{C}$., breathing air, her rectal temperature was rising steadily (Fig. 2). When the environmental temperature was lowered to $28^{\circ} \mathrm{C}$., the expected increase in $\mathrm{O}_{2}$ consumption did not occur, and the rate of rise of rectal temperature fell. The environmental temperature was then raised first to $33^{\circ} \mathrm{C}$. and then to $35^{\circ} \mathrm{C}$., and the atmosphere was enriched to $\mathbf{5 0} \%$ oxygen, without causing any rise in oxygen consumption. When the environmental temperature was again reduced to $28^{\circ} \mathrm{C}$., there was a substantial increase in $\mathrm{O}_{2}$ consumption. Replacing the atmosphere with air at $28^{\circ} \mathrm{C}$. resulted in a fall in $\mathrm{O}_{2}$ consumption to near basal level, and a fall in rectal temperature. Enriching the inspired air once more to $50 \% \mathrm{O}_{2}$ again enabled the child to increase her $\mathrm{O}_{2}$ consumption and to maintain the body temperature. It
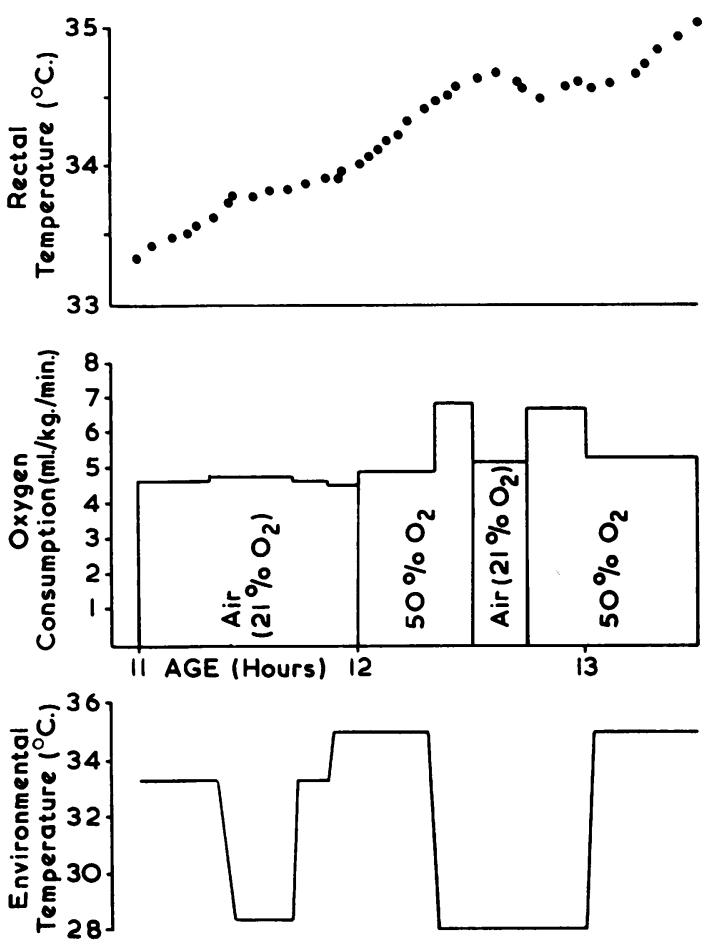

FIG. 2.-(Case 1 in text.) Rectal temperature, ambient oxygen concentration, rate of oxygen consumption, and environmental temperature, over a $2 \frac{1}{2}$-hour period, in a $2,980 \mathrm{~g}$. baby.

was concluded that the baby, who showed no cyanosis or respiratory difficulty, was hypoxic in air but not in $50 \%$ $\mathrm{O}_{2}$. Her subsequent progress was uneventful and at 1 day of age she was able to maintain her rectal temperature spontaneously in air at $28^{\circ} \mathrm{C}$. It is noteworthy that all these changes could be inferred by observation of the rectal temperature, but more rapid and definite information was obtained by measuring oxygen consumption.

Case 2 (Fig. 3). This baby was born prematurely (34 weeks' gestation) and weighed $2,070 \mathrm{~g}$. At birth she breathed at once and at 1 minute had a heart rate of 120 , good limb tone, and was pink in colour. At 2 minutes, however, there was a generalized tonic convulsion followed by apnoea, necessitating resuscitation. Immediately after spontaneous respiration had restarted at 5 minutes there was mild sternal recession. At 4 hours the respiratory rate had risen to 64 , and there was mild recession and grunting. No cause was found for the convulsion-the CSF was not blood stained.

At 22 hours, when the baby was placed in the $\mathrm{O}_{2}$ consumption incubator, she still had mild respiratory distress. At an environmental temperature of $34.5^{\circ} \mathrm{C}$., 


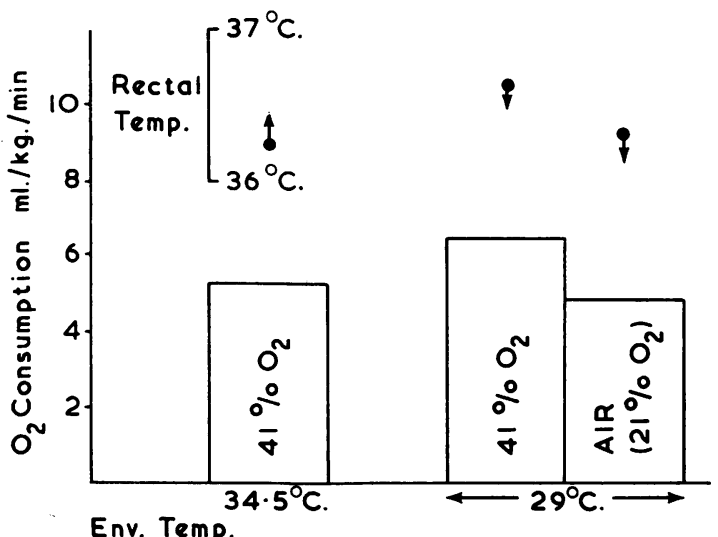

FIG. 3.-(Case 2 in text.) The effect on metabolic rate and rectal temperature of variation in incubator temperature and ambient oxygen concentration. Each measurement was made over a 10-minute period. $\mathrm{Po}_{2}$ measured while the child breathed air was $47 \mathrm{~mm}$. $\mathrm{Hg}$.

breathing $41 \% \mathrm{O}_{2}$, the rectal temperature was rising slowly. On changing the environmental temperature to $29^{\circ} \mathrm{C}$., while the child was breathing $41 \% \mathrm{O}_{2}$, there was an increase in $\mathrm{O}_{2}$ consumption (Fig. 3), but at this relatively cool temperature the rectal temperature fell slightly. While breathing air at the same cool temperature, the $\mathrm{O}_{2}$ consumption rate fell to near basal levels, and the rate of fall of rectal temperature was accelerated. It was concluded that this child was hypoxic in air and in fact the arterial $\mathrm{Po}_{2}$ estimated at the end of the observation, when the child was breathing air, was $47 \mathrm{~mm}$. $\mathrm{Hg}$. She was kept in $40 \%$ oxygen for the next 24 hours and subsequently had an uneventful recovery.

Case 3 (Fig. 4). This baby was born after 35 weeks' gestation weighing $1,960 \mathrm{~g}$. There had been a small ante-partum haemorrhage at 27 weeks. At 35 weeks the mother was examined under anaesthesia and the membranes were ruptured. The cord prolapsed and the baby was, therefore, delivered at once by lower segment caesarean section. At 1 minute, the baby was apnoeic, limp, and blue, with a heart rate of 66 . His airways were aspirated and his trachea intubated, oxygen being given by intermittent positive pressure. By 1 hour of age there was obvious subcostal recession on inspiration and he had developed severe respiratory distress, which lasted 5 days. Over this period his $\mathrm{Po}_{2}$ was consistently low (see Fig. 4) unless very high concentrations of oxygen were given (70-80\%).

At 4 days of age he was tested in the oxygen consumption incubator. At an environmental temperature of $34 \cdot 9^{\circ} \mathrm{C}$., breathing $77 \% \mathrm{O}_{2}$, his basal metabolic rate was measured; at this time the rectal temperature was rising slowly. On reducing the environmental temperature to $28 \cdot 2^{\circ} \mathrm{C}$., while he was breathing $77 \% \mathrm{O}_{2}$, there was a rise in $\mathrm{O}_{2}$ consumption, though the rectal temperature fell slightly. When tested in $54 \% \mathrm{O}_{2}$ and $42 \% \mathrm{O}_{2}$ for

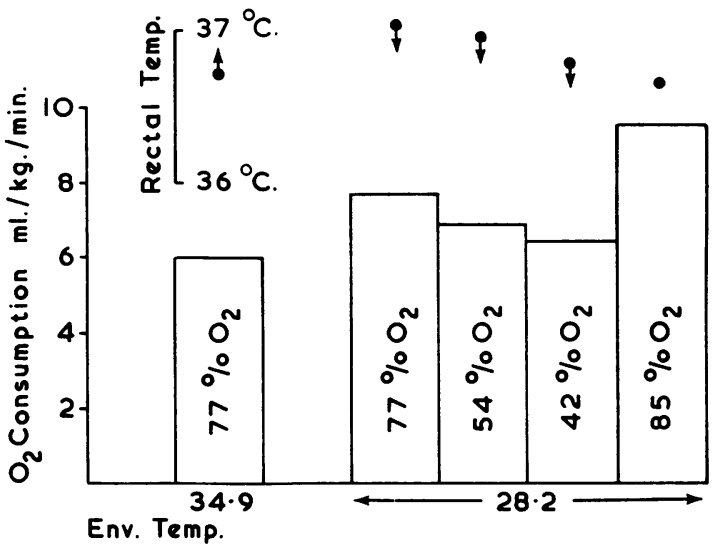

Fig. 4.-(Case 3 in text.) The effect on metabolic rate and rectal temperature of variation in incubator temperature and ambient oxygen concentration. Each measurement was made over a 10-minute period. $\mathrm{Po}_{2}$ while breathing $70 \% \mathrm{O}_{2}$ was $90 \mathrm{~mm}$. $\mathrm{Hg}$; $\mathrm{Po}_{2}$ while breathing $54 \% \mathrm{O}_{2}$ was $54 \mathrm{~mm}$. $\mathrm{Hg}$; and $\mathrm{Po}_{2}$ while breathing $34 \% \mathrm{O}_{2}$ was $22 \mathrm{~mm}$. $\mathrm{Hg}$.

10-minute periods (Fig. 4), the $\mathrm{O}_{2}$ consumption rate was reduced in steps to near basal levels, and the rate of fall of rectal temperature was increased. Subsequently, giving him $85 \% \mathrm{O}_{2}$, still at an environmental temperature of $28 \cdot 2^{\circ} \mathrm{C}$., there was a substantial rise in $\mathrm{O}_{2}$ consumption and the rectal temperature remained stable. Arterial $\mathrm{PO}_{2}$ estimations just before and just after the testing period were $22 \mathrm{~mm}$. $\mathrm{Hg}$ in $34 \% \mathrm{O}_{2}, 54 \mathrm{~mm}$. $\mathrm{Hg}$ in $54 \%$ $\mathrm{O}_{2}$, and $90 \mathrm{~mm}$. $\mathrm{Hg}$ in $70 \% \mathrm{O}_{2}$. On the sixth day of life he had recovered from his respiratory distress and made good progress.

Case 4 (Fig. 5). This baby was born by breech delivery at 29 weeks' gestation weighing 1,180 g. At 1 minute she was apnoeic, limp, and blue, with a heart rate of 80 . She was, therefore, intubated and artificially ventilated by intermittent positive pressure. She developed severe respiratory distress, complicated by repeated apnoeic spells, and needed very high concentrations of environmental oxygen for the first few days of life. At 48 hours an exchange transfusion was performed for jaundice of prematurity. Unlike most babies with respiratory distress, her respiratory difficulties persisted for weeks.

At 48 hours, at the height of her illness, her $\mathrm{Po}_{2}$ in air was only $19 \mathrm{~mm}$. $\mathrm{Hg}$ and in $86 \% \mathrm{O}_{2}$ only $54 \mathrm{~mm}$. $\mathrm{Hg}$. She was kept in over $60 \% \mathrm{O}_{2}$ until tested on the eleventh day in the oxygen consumption incubator. She had a satisfactory metabolic response to cooling to $29 \cdot 7^{\circ} \mathrm{C}$. (Fig. 5b) while breathing $62 \% \mathrm{O}_{2}$ and $45 \% \mathrm{O}_{2}$, but in $35 \% \mathrm{O}_{2}$ there was no response. She was maintained at $55 \% \mathrm{O}_{2}$. On the seventeenth day she had a satisfactory metabolic response to cooling to $28 \cdot 8^{\circ} \mathrm{C}$. (Fig. 5c) while breathing $47 \% \mathrm{O}_{2}$ and $37 \% \mathrm{O}_{2}$, but not in $23 \% \mathrm{O}_{2}$. She was now kept in $40 \% \mathrm{O}_{2}$. On the 23 rd day (Fig. 5d) 
(a)

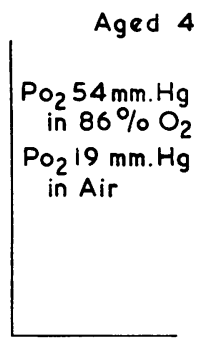

Env. Temp.

(d) (b)

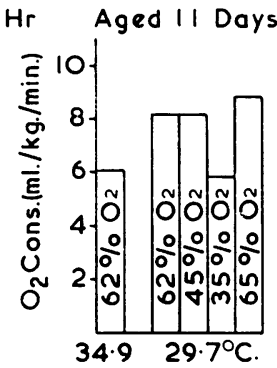

Aged 23 Days Aged 26 Days

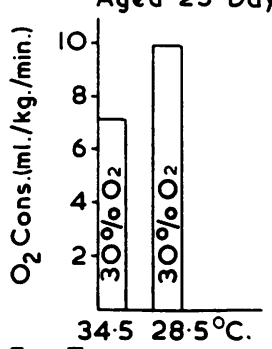

Env. Temp.

FIG. 5.-(Case 4 in text.) Changes in oxygen requirements over the period of 1 month in a baby with severe and persistent respiratory distress. $(a)-(f)$ stages as stated in the figure.

she had a satisfactory response in $30 \% \quad \mathrm{O}_{2}$ but was cyanosed in air and so was maintained at $30-35 \%$ oxygen. At 26 days (Fig. 5e) there seemed to be some response at $23 \% \mathrm{O}_{2}$ but at 31 days (Fig. 5f) she still needed $26 \% \mathrm{O}_{2}$. Her subsequent recovery was gradual. Her eyes have been examined regularly by an ophthalmologist, and at $4 \frac{1}{2}$ months of age no evidence of retrolental fibroplasia has been seen.

Case 5 (Fig. 6). This baby was born at home to an unmarried mother who had concealed her pregnancy. Gestation was uncertain but birth weight was 1,640 g. The baby was thought to be dead at birth and was left lying wet and uncovered in a cold room. When he was noted to be gasping he was transferred to the Neonatal Ward, where he was found to have a rectal temperature of $29 \cdot 5^{\circ} \mathrm{C}$. He was a small oedematous immature baby, breathing spontaneously but irregularly, and without any obvious recession or grunting.

In the oxygen consumption incubator at an environmental temperature of $31 \cdot 8^{\circ} \mathrm{C}$. (rectal temperature had by now risen to $31^{\circ} \mathrm{C}$.) and breathing $33 \% \mathrm{O}_{2}$, the rectal temperature was rising steadily, but the $\mathrm{O}_{2}$ consumption rate was very low $(3 \mathrm{ml} . / \mathrm{kg} . / \mathrm{min}$.). On replacing with air at the same temperature, the child became slightly 'dusky', the $\mathrm{O}_{2}$ consumption rate fell, and the rectal
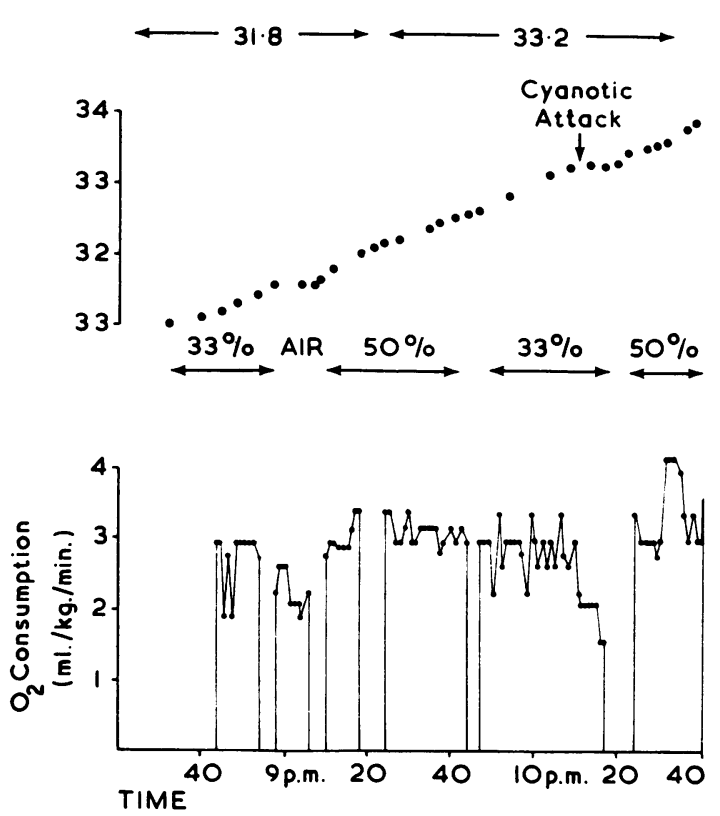

FIG. 6.-(Case 5 in text.) Environmental temperature, rectal temperature, ambient oxygen concentration, and rate of $\mathrm{O}_{2}$ consumption in the course of rewarming a hypothermic premature baby.

temperature no longer rose. Giving $50 \% \quad \mathrm{O}_{2}$ was associated with a rise in rectal temperature and in rate of $\mathrm{O}_{2}$ consumption. As the body temperature rose the environmental temperature was increased to $33 \cdot 2^{\circ} \mathrm{C}$. There was at this stage no difference in rate of rise of rectal temperature or of rate of $\mathrm{O}_{2}$ consumption whether the child was given $50 \% \mathrm{O}_{2}$ or $33 \% \mathrm{O}_{2}$. At 10.15 p.m. the child had a cyanotic episode associated with a fall in $\mathrm{O}_{2}$ consumption rate and in the rate of rise of rectal temperature. He was subsequently given $50 \% \mathrm{O}_{2}$. It was not considered justifiable to test this baby's $\mathrm{O}_{2}$ consumption at a lower environmental temperature. $\mathrm{He}$ died 4 hours later after an episode of apnoea and was found at necropsy to have a pulmonary haemorrhage-a common finding in cold babies. Again an accurate record of the rectal temperature gave the same information as measurement of $\mathrm{O}_{2}$ consumption.

Case 6 (Fig. 7). This baby was born prematurely (probably 28 weeks' gestation) weighing 1,020 g. At birth, respiration started spontaneously, but within minutes there was rapid respiration with grunting and recession. He went on to develop severe clinical respiratory distress together with episodes of apnoea.

At 24 hours in the oxygen consumption incubator at an environmental temperature of $32^{\circ} \mathrm{C}$., breathing $40 \% \mathrm{O}_{2}$, the child's rectal temperature was gradually falling, 

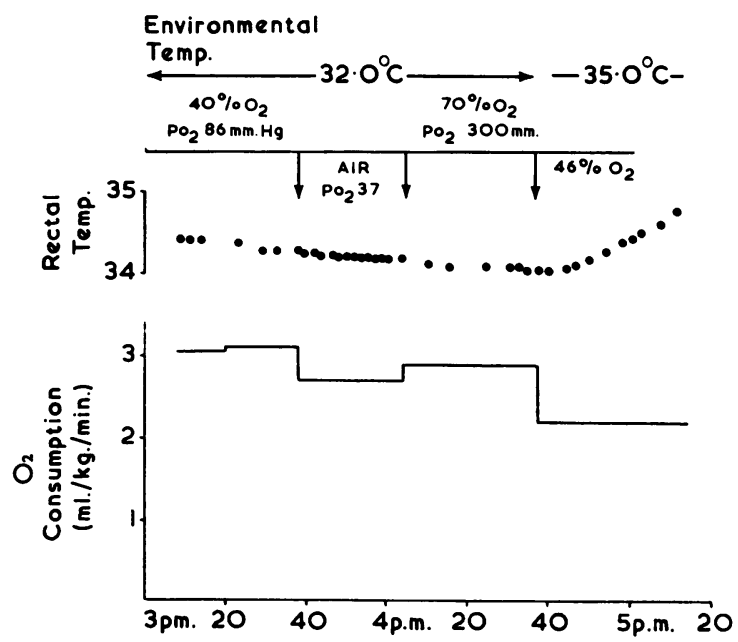

Fig. 7.-(Case 6 in text.) Environmental temperature, ambient oxygen concentration, arterial $\mathrm{Po}_{2}$, rectal temperature, and rate of $\mathrm{O}_{2}$ consumption in a $1,020 \mathrm{~g}$. premature baby who subsequently died with an intraventricular haemorrhage.

indicating that this temperature was below the neutral range for this child. When breathing air there was a small fall in oxygen consumption rate, and when breathing $70 \% \mathrm{O}_{2}$ the rate returned very nearly to that obtaining in $40 \%$. However, neither of these changes was reflected in the record of the rectal temperature which continued to fall slowly. Estimations of arterial $\mathrm{Po}_{2}$ while the child breathed the respective $\mathrm{O}_{2}$ concentrations were carried out during or immediately after the test period and are entered in Fig. 7. Although hypoxia was abolished by giving $70 \% \mathrm{O}_{2}$ (in fact a dangerously high $\mathrm{PO}_{2}$ was achieved), this was not reflected in the rate of oxygen consumption. This child's failure to achieve a metabolic response was clearly not due only to hypoxia. He subsequently died, and at necropsy he was found to have pulmonary atelectasis with hyaline membrane and an intraventricular cerebral haemorrhage.

Case 7 (Fig. 8). This baby was born after 33 weeks' gestation weighing $2,100 \mathrm{~g}$. She developed respiratory distress and was treated with added oxygen. At 24 hours she still had rapid respirations and sternal recession. During a test period, the incubator temperature was maintained at $31 \cdot 7^{\circ} \mathrm{C}$. While she was breathing air her rectal temperature was falling. When the $\mathrm{O}_{2}$ concentration of the atmosphere was increased to 40$50 \%$, the rectal temperature stabilized. Reducing the $\mathrm{O}_{2}$ concentration once more to $21 \%$ was followed by a fall in rectal temperature. Environmental $\mathrm{O}_{2}$ concentrations of $50 \%$ and $32 \%$ were associated with a stable rectal temperature. It was concluded that this child needed at least $32 \% \mathrm{O}_{2}$ in her atmosphere. She subsequently made a good recovery.
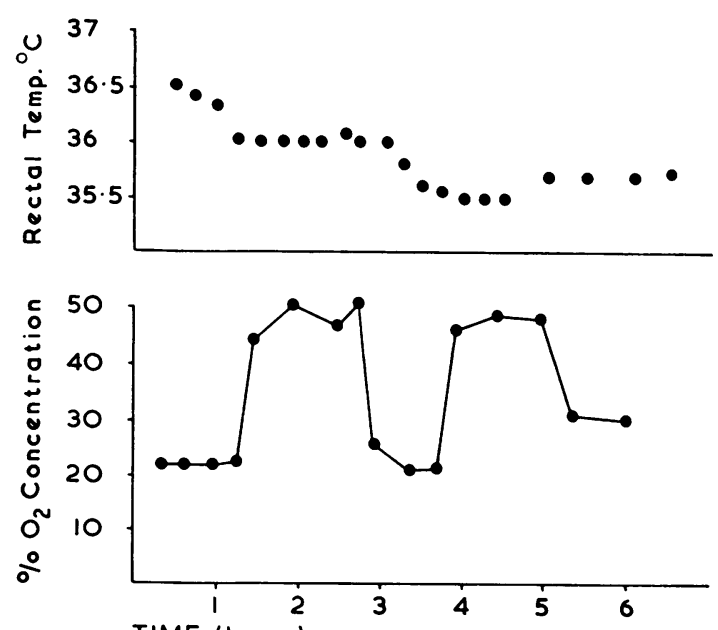

TIME (hours)

FIG. 8.-(Case 7 in text.) Variation of rectal temperature with $\mathrm{O}_{2}$ concentration of inspired air in a premature baby with respiratory distress. Incubator temperature was maintained at $31 \cdot 7^{\circ} \mathrm{C}$.

Case 8 (Fig. 9). This baby, the smaller of twins, was born at 33 weeks' gestation weighing $920 \mathrm{~g}$. She developed respiratory distress within 2 hours of birth. At 24 hours, while breathing $30 \% \mathrm{O}_{2}$ and with the incubator temperature maintained at $33^{\circ} \mathrm{C}$. (as it was throughout the period of observation), her rectal
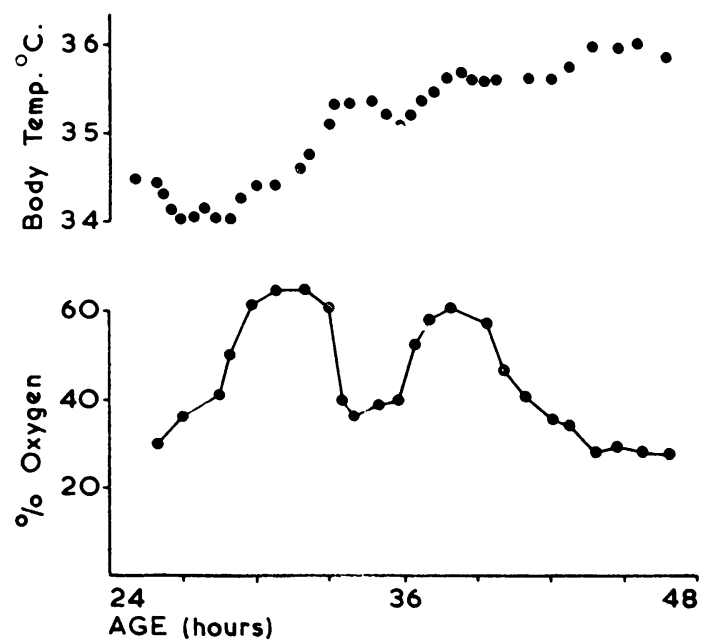

FIG. 9.-(Case 8 in text.) Variation of rectal temperature with $\mathrm{O}_{2}$ concentration of inspired air in a premature baby with respiratory distress. Incubator temperature was maintained at $33^{\circ} \mathrm{C}$. 
temperature was falling. Raising the concentration of oxygen in the inspired air to $40 \%$ and then $60 \%$ was associated with a stabilization and then a rise in rectal temperature: reducing the $\mathrm{O}_{2}$ concentration to between 35 and $40 \%$ was accompanied by a fall in rectal temperature, which was reversed by once more raising the $\mathrm{O}_{2}$ concentration to $60 \%$. At 39 hours of age when the child was clinically somewhat better, reducing the $\mathrm{O}_{2}$ concentration to $30 \%$ was no longer accompanied by a fall in rectal temperature which in fact continued to rise.

Case 9. This child was born after 32 weeks' gestation and weighed $1,860 \mathrm{~g}$. at birth. At 1 minute respiration was established and the child was in good condition. At 2 hours of age she had several episodes of apnoea, and then developed increasing dyspnoea. At 4 hours of age her respiratory rate was 80 , and there was grunting, subcostal recession, and frequent apnoeic episodes. At this time arterial $\mathrm{Po}_{2}$, while the child breathed $100 \%$ oxygen, was $42 \mathrm{~mm}$. $\mathrm{Hg}$, and $\mathrm{PCO}_{2}$ was $35 \mathrm{~mm}$. $\mathrm{Hg}$.

When aged 28 hours she was tested in the $\mathrm{O}_{2}$ consumption incubator. Breathing $91 \%$ oxygen at an environmental temperature of $34 \cdot 6^{\circ} \mathrm{C}$. her $\mathrm{O}_{2}$ consumption rate was $5.75 \mathrm{ml} . / \mathrm{kg} . / \mathrm{min}$. Reducing the ambient temperature to $27 \cdot 9^{\circ} \mathrm{C}$., while she breathed $91 \% \quad \mathrm{O}_{2}$ was associated with an increase in $\mathrm{O}_{2}$ consumption rate to $7.3 \mathrm{ml} . / \mathrm{kg}$. $/ \mathrm{min}$., and an arterial $\mathrm{Po}_{2}$ measured at this time was $44 \mathrm{~mm}$. $\mathrm{Hg}$. At the same cool temperature, the ambient oxygen concentration was reduced to $62 \%$. This was associated with a fall in $\mathrm{O}_{2}$ consumption rate to $5.9 \mathrm{ml} . / \mathrm{kg}$. $/ \mathrm{min}$. and a fall in rectal temperature. Her arterial $\mathrm{PO}_{2}$ measured simultaneously was $32 \mathrm{~mm}$. $\mathrm{Hg}$.

She was nursed in $95 \%$ oxygen and an environmental temperature of $34^{\circ} \mathrm{C}$. but died at 48 hours after an apnoeic episode. Necropsy showed pulmonary atelectasis and hyaline membrane.

Case 10. This child was born by breech delivery after 33 weeks' gestation weighing $1,860 \mathrm{~g}$. At 1 minute he was cyanosed, apnoeic, limp, and unresponsive, with a heart rate of 60 . He was intubated and given artificial respiration, and spontaneous respiration started by 4 minutes, but at 10 minutes there was already subcostal recession, and he went on to develop obvious grunting and dyspnoea.

At 13 hours he was tested in the $\mathrm{O}_{2}$ consumption incubator. At an environmental temperature of $35.4^{\circ} \mathrm{C}$. his $\mathrm{O}_{2}$ consumption rate was $4.7 \mathrm{ml} . / \mathrm{kg} . / \mathrm{min}$. At an environmental temperature of $26 \cdot 6^{\circ} \mathrm{C}$., breathing $35 \%$ $\mathrm{O}_{2}$, his metabolic rate rose to $6.9 \mathrm{ml} . / \mathrm{kg} . / \mathrm{min}$. and a simultaneous arterial $\mathrm{Po}_{2}$ was $64 \mathrm{~mm}$. $\mathrm{Hg}$. At the same cool temperature, breathing air, the metabolic response was reduced to a rate of $6.2 \mathrm{ml} . / \mathrm{kg}$. $/ \mathrm{min}$., at a time when arterial $\mathrm{Po}_{2}$ was $46 \mathrm{~mm}$. $\mathrm{Hg}$. In this child the metabolic response to cold was impaired but not abolished at a $\mathrm{Po}_{2}$ of $46 \mathrm{~mm}$. $\mathrm{Hg}$. He subsequently recovered from his respiratory distress.

\section{Discussion}

Our data confirm the thesis that hypoxia in a newborn baby impairs or abolishes his ability to achieve a metabolic response to cooling. In some of the babies (e.g. Cases 3, 4, 9, and 10) hypoxaemia was proved by measurement of arterial $\mathrm{Po}_{2}$; in all the others there was good circumstantial and clinical evidence of hypoxia. When a baby has a poor or absent metabolic response to cooling, and when the response is restored by enriching the atmosphere with oxygen (all other environmental factors remaining constant), it suggests (1) that he was hypoxic before the added oxygen, and (2) that adding oxygen has corrected the hypoxia. A failure of metabolic response, which is not corrected by enriching the oxygen in his atmosphere, may be explained in one of two ways: first, the enrichment achieved may have been insufficient, or the failure may have been due to other factors. Among the other factors that we have found to inhibit a metabolic response to cooling are symptomatic hypoglycaemia, various drugs, cerebral damage, and severe hypothermia. It follows that if an attempt to restore the metabolic response by putting the baby in a high concentration of oxygen fails, it may be dangerous (in terms of $\mathrm{Po}_{2}$ levels which, when higher than normal, can cause retrolental fibroplasia) to increase the $\mathrm{O}_{2}$ concentration still further. If, however, adding $\mathrm{O}_{2}$ restores the metabolic response, and the ambient $\mathrm{O}_{2}$ concentration is then kept at not more than $20 \%$ above the level at which the response is impaired, probably there is little danger of causing retrolental fibroplasia, because even in babies with normal lungs, the inspired $\mathrm{O}_{2}$ concentration at which there is danger of causing retrolental fibroplasia $(40 \%)$ is at least $20 \%$ above that at which the metabolic response is impaired $\left(<15 \% \mathrm{O}_{2}\right)$.

In newborn small animals the metabolic response is impaired at inspired $\mathrm{O}_{2}$ concentrations below $15 \%$ and is abolished when the inspired $\mathrm{O}_{2}$ concentration falls below 8\% (Adamsons, 1959; Hill, 1959). These percentages would correspond very roughly with arterial $\mathrm{Po}_{2}$ of 75 and $30 \mathrm{~mm}$. $\mathrm{Hg}$, respectively. Our data, admittedly inadequate (Cases 3, 4, 9, and 10), suggest that in the human baby the metabolic response is seriously impaired at an arterial $\mathrm{Po}_{2}$ of 45 to $55 \mathrm{~mm}$. $\mathrm{Hg}$ and abolished at a $\mathrm{Po}_{2}$ of about $30 \mathrm{~mm}$. Hg. One would expect cyanosis at this $\mathrm{Po}_{2}$, but Gupta (personal communication) has repeatedly observed dark blue arterial blood with $\mathrm{Po}_{2}$ levels of less than $30 \mathrm{~mm} . \mathrm{Hg}$ in babies who are clinically pink. In fact, dead babies often remain pink if kept in oxygen (Tizard, 1964). More $\mathrm{Po}_{2}$ data of this sort are being sought. It is obviously 
unethical to test the situation artificially in normal babies and one must wait for cases in which disease has produced the test situation.

Even in the absence of a metabolic chamber, useful information may be gained by monitoring the rectal temperature, provided the incubator is equipped to maintain a very stable environment, though some caution and understanding are necessary for the interpretation of the results. Most commercial incubators fail to provide the exacting conditions needed for this test. In particular, babies lose heat by radiation in single-walled incubators, so that an air temperature within the so-called neutral zone does not guarantee a neutral thermal environment. Over the test period the baby must be kept at a constant environmental temperature just below the neutral range which varies in individual babies. In most small premature babies $31-32^{\circ} \mathrm{C}$. is below the neutral range and in most full-term babies $29-30^{\circ} \mathrm{C}$. is below the neutral range (Adams, Fujiwara, Spears, and Hodgman, 1964a, b; Brück, 1961, and personal observations). These environmental temperatures are unacceptably low for nursing some sick babies, so the test period may have to be limited. Monitoring the rectal temperature by repeated insertion of a clinical thermometer is not very satisfactory. The changes sought are small, and factors such as inadequate time for equilibration, and irregular depth of insertion (Karlberg, 1949), may lead to inaccuracies. We prefer a thermistor or thermocouple inserted to about $10 \mathrm{~cm}$. and strapped in place. A device for automatic recording is obviously an advantage. Even with good facilities and equipment one must be careful that large changes in heat lost or gained by evaporation or radiation (Agate and Silverman, 1963) are not affecting temperature change. If, in an environmental temperature below the neutral range, a child's rectal temperature is stable or rising, it suggests he is not seriously anoxic (unless the anoxia is chronic (Brück, Adams, and Brück, 1962).) If a falling rectal temperature is corrected by increasing the ambient $\mathrm{O}_{2}$ concentration, without other environmental change, it suggests he was previously anoxic and that this has been corrected. If the rectal temperature is falling and that fall is not corrected by increasing ambient oxygen, it may mean that still higher concentrations are needed, or that some factor other than hypoxia is preventing a metabolic response (Case 6, Fig. 7). Caution and thought are needed in deciding the next step in such a case. We have found it safe and convenient to make changes in $\mathrm{O}_{2}$ concentration in steps of $10-20 \%$.

In many newborn animals heat is produced by non-shivering thermogenesis (Scopes and Tizard,
1963). There is good evidence that in the rabbit a substantial amount of this heat is produced in brown fat (Dawkins and Hull, 1964) and in the human baby there is circumstantial evidence that the same thermogenesis may apply (Dawkins and Scopes, 1965). A 'small for dates' baby with hypothermia, admitted to this hospital recently, had no metabolic response to cold at an age and in a state when he would be expected to have no brown fat (Aherne and Hull, 1964). There was no metabolic response to cooling and no measurable glycerol in his blood. Two weeks later, when he was well covered with fat, he showed a normal metabolic response to cooling, and the cooling was associated on this occasion with a rise in plasma glycerol. Most newborn babies have brown fat in the axilla (Aherne and Hull, 1964), and it is possible that monitoring axillary temperature (near the site of heat production in the brown fat) may be a more sensitive index of metabolic response than monitoring rectal temperature. Observations on these lines are now in progress.

It is clear that monitoring rectal temperature can give valuable information for assessing oxygen requirements in babies. It is especially satisfactory since it depends on the physiological response of the baby rather than on arbitrarily determined 'levels'. The information, if it is to be used clinically, must obviously be assessed in relation to the total clinical situation of the baby including its disease, colour, respiration, and general clinical state.

\section{Conclusion}

A baby's need for oxygen enrichment of the inspired air can be assessed by measuring his ability to produce heat. Indirect evidence of this ability can be gained by monitoring the rectal temperature in certain thermal conditions, and this information can be valuable clinically. For a discussion of the limitations of this method and the precautions necessary the reader is referred to the text.

We are grateful to the trustees of the Sir William Coxen trust fund for equipment and laboratory facilities, and to the Nuffield Foundation and to H. J. Heinz and Co. Ltd. for grants which made this work possible. We also wish to thank Dr. J. M. Gupta who performed the $\mathrm{PO}_{2}$ estimations and to Professor J. P. M. Tizard and Dr. J. A. Davis for advice and help in the preparation of this paper.

\section{REFERENCES}

Adams, F. H., Fujiwara, T., Spears, R., and Hodgman, J. (1964a). Gaseous metabolism in premature infants at $32-34^{\circ} \mathrm{C}$. ambient temperature. Pediatrics, 33, 75.

,$--\frac{1}{,}$, and $\frac{1}{i b i d}(1964 \mathrm{~b})$. Temperature regulation in 
Adamsons, K., Jr. (1959). Breathing and the thermal environment in young rabbits. F. Physiol. (Lond.), 149, 144.

Agate, F. J., Jr., and Silverman, W. A. (1963). The control of body temperature in the small newborn infant by low-energy infrared radiation. Pediatrics, 31, 725 .

Aherne, W., and Hull, D. (1964). The site of heat production in the newborn infant. Proc. roy. Soc. Med., 57, 1172.

Ashton, N. (1964). Retrolental fibroplasia in kittens. Personal communication to Tizard (1964).

Avery, M. E., and Oppenheimer, E. H. (1960). Recent increase in mortality from hyaline membrane disease. $f$. Pediat., $57,553$.

Brück, K. (1961). Temperature regulation in the newborn infant. Biol. Neonat. (Basel), 3, 65.

- Adams, F. H., and Brück, M. (1962). Temperature regulation in infants with chronic hypoxemia. Pediatrics, 30, 350

Campbell, E. J. M. (1960). Respiratory failure; the relation between oxygen concentrations of inspired air and arterial blood. Lancet, 2, 10.

Craig, J. M., Fenton, K., and Gitlin, D. (1958). Obstructive factors in the pulmonary hyaline membrane syndrome in asphyxia of the newborn. Pediatrics, 22, 847.

Davis, J. A., and Tizard, J. P. M. (1961). Practical problems of neonatal paediatrics considered in relation to animal physiology. Brit. med. Bull., 17, 171.

Dawes, G. S., Jacobson, H. N., Mott, J. C., and Shelley, H. J. (1960). Some observations on foetal and new-born rhesus monkeys. f. Physiol. (Lond.), 152, 271.

-, and Mestyán, J. (1963). Changes in the oxygen consumption of new-born guinea-pigs and rabbits on exposure to cold. ibid., 168, 22.
Dawkins, M. J. R., and Hull, D. (1964). Brown adipose tissue and the response of new-born rabbits to cold. ibid., 172, 216

—, and Scopes, J. W. (1965). Non-shivering thermogenesis and brown adipose tissue in the human new-born infant. Nature (Lond.), 206, 201.

Hill, J. R. (1959). The oxygen consumption of new-born and adult mammals. f. Physiol. (Lond.), 149, 346.

Karlberg, P. (1949). The significance of depth of insertion of the thermometer for recording rectal temperature. Acta paediat. (Uppsala), 38, 359.

Kinsey, V. E. (1956). Retrolental fibroplasia: cooperative study of retrolental fibroplasia and the use of oxygen. Arch. Ophthal., 56, 481.

McDonald, A. D. (1963). Cerebral palsy in children of very low birth weight. Arch. Dis. Childh., 38, 579.

Oliver, T. K., Jr., and Karlberg, P. (1963). The effect of environmental temperature and $15 \%$ oxygen on the gaseous metabolism of newborn infants. Acta paediat. (Uppsala), Suppl. 140, p. 51.

Patz, A., Hoeck, L. E., and De La Cruz, E. (1952). Studies on the effect of high oxygen administration in retrolental fibroplasia. I. Nursery observations. Amer. F. Ophthal., 35, 1248.

Scopes, J. W., and Tizard, J. P. M. (1963). The effect of intravenous noradrenaline on the oxygen consumption of new-born mammals. f. Physiol. (Lond.), 165, 305.

Tizard, J. P. M. (1964). Indications for oxygen therapy in the newborn. Pediatrics, 34, 771.

Warley, M. A., and Gairdner, D. (1962). Respiratory distress syndrome of the newborn-principles in treatment. Arch. Dis. Childh., 37, 455. 